\title{
Cognitive factors associated with brucellosis preventive behaviours among diagnosed patients: an application of Empowerment Model
}

Towhid Babazadeh, ${ }^{1}$ Haidar Nadrian, ${ }^{2}$ Soheila Ranjbaran, ${ }^{3}$ Hamed Rezakhani-Moghaddam ${ }^{4}$ and Mehran Aghemiri ${ }^{5}$

${ }^{1}$ Department of Public Health, Sarab Faculty of Medical Sciences, Sarab, Islamic Republic of Iran. ${ }^{2}$ Social Determinants of Health Research Center, Tabriz University of Medical Sciences, Tabriz, Islamic Republic of Iran. ${ }^{3}$ Department of Health Education and Promotion, School of Health, Tehran University of Medical Sciences, Tehran, Islamic Republic of Iran. ${ }^{4}$ Department of Public Health, Khalkhal University of Medical Sciences, Khalkhal, Islamic Republic of Iran. ${ }^{5}$ Department of Medicine, Tarbiat Modares University, Tehran, Islamic Republic of Iran. (Correspondence to: Haidar Nadrian: haidarnadrian@gmail.com).

\begin{abstract}
Background: Brucellosis is an endemic disease in many countries, especially in the Mediterranean region, as well as countries such as the Islamic Republic of Iran. Despite the preventive measures against brucellosis adopted in different countries throughout the world, the disease is still a public health concern.
\end{abstract}

Aims: Our aim in the present study was to examine the cognitive factors associated with Brucellosis Preventive Behaviours (BPBs) among diagnosed patients utilizing Empowerment Model.

Methods: In 2013, applying a cross-sectional study, all 238 patients with brucellosis in Chaldoran County, Islamic Republic of Iran, were recruited to answer a researcher-made EM-based questionnaire and BPBs Scale through interview.

Results: Hierarchical multiple linear regressions were performed with BPBs as the outcome variable. Predictors for this variable, according to their natures, were classified in two different blocks. In the first block, significant effect was found on $\mathrm{BPBs}$ by demographic variables $(\triangle \mathrm{R} 2=0.301)$. In the second block, the level of education, knowledge, and self-efficacy were significant predictors $(P<0.001)$ of BPBs $(\triangle \mathrm{R} 2=0.808)$.

Conclusions: The Empowerment Model was found as a helpful framework in predicting the risk factors of BPBs. Health care providers in low- and middle-income countries should consider the patients' knowledge on the disease and their level of self-efficacy to perform BPBs as the core categories of empowerment while designing brucellosis prevention programmes.

Keywords: Brucellosis, preventive behaviours, knowledge, self-efficacy, Empowerment Model

Citation: Babazadeh T; Nadrian H; Ranjbaran S; Rezakhani-Moghaddam H; Aghemiri M. Cognitive factors associated with Brucellosis preventive behaviours among diagnosed patients: an application of Empowerment Model. East Mediterr Health J. 2019;25(8):567-574. https://doi.org/10.26719/ emhj.18.062

Received: 04/10/16; accepted: 28/11/17

\section{Introduction}

Brucellosis is the most common zoonosis disease worldwide and causes infection in domestic animals, wildlife and humans (1). Human brucellosis is a bacteraemia process that presents an undulating period, with a high tendency towards relapses which evolves into a chronic state with frequent reinfection (2). Brucella infection causes abortion, preterm delivery and intra-uterine infection among animals (3). Symptoms of brucellosis such as intermittent fever, chills, malaise, arthralgia, diaphoresis, myalgia, headache, anorexia, and fatigue-like influenza are generally non-specific to humans (4).

Brucellosis is an endemic disease in many countries, especially in the Mediterranean region, including Kuwait, Saudi Arabia and some parts of Africa $(1,3,5,6)$. The World Health Organization (WHO) has reported about 500000 cases of brucellosis worldwide, and 10 000-20 000 cases per year in Europe (7). Based on the world's map of brucellosis (2006), the brucellosis incidence in the Islamic Republic of Iran was 50 to 500 per 100000 people (8). In a previous study, the prevalence of brucellosis in the Islamic Republic of Iran was reported as high in several provinces including Hamedan, Kurdistan, Lorestan, and West and East Azerbaijan (5). Despite the preventive measures against brucellosis adopted in different countries throughout the world, particularly the Mediterranean and the Islamic Republic of Iran, the disease is still a public health concern (9).

Brucellosis is transmitted through different ways, including inhalation of contaminated air, dust soaked in urine and faeces of infected animals, direct contact with infected animals, and consumption of dairy products $(2-5)$. All of these transmission routes can be mitigated by performing preventive behaviours, which have been emphasized in several previous studies $(3,10,11)$.

Theory-based interventions may be more effective in influencing brucellosis preventive behaviours (BPBs) in comparison to other approaches, as they provide a framework to develop health promotion interventions and guide the evaluation of these interventions (12). To our knowledge, few studies have used a framework to promote BPBs in rural areas $(10,13)$. In a study, Oruogi et al. applied the PRECEDE-PROCEED model as a framework to reduce the brucellosis incidence in rural areas of Khomain County, Islamic Republic of Iran. The results of 
their intervention showed a remarkable decrease in the incidence of brucellosis from 147 to 43 cases per 100000 after a nine months' follow-up (10). In a study conducted by Babaei et al., cognitive factors such as self-efficacy and perceived susceptibility were associated with BPBs (11).

Several earlier studies (10,11,14-17), as well as the Ottawa Charter on Health Promotion (14), have emphasized the effectiveness of empowerment as a strategy to prevent diseases and promote health. Moreover, Sausa et al. (15), concluded that knowledge raising alone is not enough to change behaviour and, therefore, emphasized on empowerment as a strategy to promote health-related behaviours.

Empowering patients begins with the provision of information and training, and ends with the active participation of patients in the decision-making process about their disease and performing health promoting behaviours (16). Empowerment may happen effectively through education, but participation plays a vital role in empowering members to deal with the nature of their illness and to improve the capacity of their self-care for health promotion (17). Masoodi et al. evaluated the effects of a family-centered empowerment model on skill, attitude and knowledge of multiple sclerosis (MS) patients' caregivers and found that empowering the caregivers promoted their knowledge, attitude and skills on giving more efficient care to their patients (18).

In the present study, the Empowerment Model was used as a framework to determine the factors associated with empowering the brucellosis patients to perform BPBs. This model provides a framework to empower patients and their families in the areas where patients need intervention (19). EM was developed by Elhani (2002) and since then has been applied as a framework to intervene in health-related behaviours $(20,21)$. The EM constructs includes: 1) knowledge (including facts, information and skills that are acquired by a person through experience or education); 2) Attitude (positive or negative evaluation of the behaviour by individuals) (2), and self-efficacy (a personal belief of ability to carry out the recommended plan of action successfully); and 3) self-esteem (feeling valued) (21).

Identifying brucellosis influential factors in the present study may be useful in designing empowermentbased interventional efforts aiming at brucellosis prevention. The questions that guided the study were as follows: 1) May the cognitive factors be associated with BPBs among the diagnosed patients? 2) To what extent might the cognitive factors of Empowerment Model be associated with BPBs among diagnosed patients?; and 3) Might EM be applied as a framework for designing empowerment-based interventional programmes aimed at brucellosis recurrence prevention among diagnosed patients? Therefore, our aim in the present study was to examine the cognitive factors associated with BPBs among patients diagnosed with brucellosis utilizing the Empowerment Model model.

\section{Methods}

\section{Participants and procedure}

This cross-sectional study was carried out from April to November 2013. Through census, all the 238 patients with brucellosis in Chaldoran were recruited to participate in the study. All those who were satisfied with participation in the study and were also diagnosed with brucellosis were included in the study.

Ethical approval for the study was provided from the Ethics Committee in Tehran University of Medical Sciences (Ethical Code was 98382). Before the implementation of the study, the purpose was explained to the participants and all signed consent forms. Data were collected using face-to-face interviews conducted in a consultation room at Health Houses by two trained healthcare providers. Each interview lasted for 35 to 40 minutes.

\section{Measures}

The instruments used for data collection were researcher-prepared questionnaires. In order to confirm the content validity of the instruments, a panel of experts involving four scholars in the areas of health education and a physician with specialty in infectious diseases, reviewed and assessed the questions orally by evaluating the appropriateness and relevance of the items to brucellosis patients, response format and confirmed them to be representative of the constructs. The responses from the panel of experts were used to revise and modify the tools, which were then pilot tested by a sample of brucellosis patients to examine their utility. The pilot study was conducted to examine the utility of the instruments and to identify the problems/benefits associated with the design.

The first draft was prepared following consultation with the research team. The questionnaire was pilot tested with 20 brucellosis patients. The data were used to estimate the internal consistency of the scales, using Cronbach's coefficient alpha. The content validity of the scales was also established. This pilot sample was not included in the final sample. For data collection, a questionnaire consisting of demographic characteristics (age, gender, level of education, residency and occupation), Empowerment Model constructs (Knowledge, Attitude, Self-efficacy and Self-esteem) and BPBs were prepared.

The Brucellosis Knowledge Questionnaire (BKQ) was prepared by the researchers to measure knowledge towards the brucellosis disease. BKQ included 19 items. An item example is as follows: "boiling milk for at least five minutes destroys the brucellosis microbes". The respondents should select 'Yes', 'No' or 'don't know' for each item. For a correct answer a score of 3 was assigned and for incorrect answer and "I don't know", the scores of 1 and 2 were considered, respectively. The possible score ranged from 19 to 57 (Cronbach $\alpha=0.82$ ).

The Brucellosis Attitude Questionnaire (BAQ) was a ten-item scale developed to measure the attitudes of 
patients towards BPBs. The response format was based on a five-point Likert-type scaling (five = totally agree, four $=$ agree, three $=$ no idea, two $=$ disagree and one $=$ totally disagree). Examples of BAQ items are: animals with brucellosis should be separated from other animals; boiling milk is a suitable method to destroy brucellosis germs. The theoretical range was 10-50, in which higher scores indicated more positive attitude toward BPBs (Cronbach $\alpha=0.78$ ).

The Brucellosis Self-Efficacy scale (BSES) was also a researcher-prepared seven-item scale developed to measure the self-efficacy towards BPBs. Again, a fivepoint Likert-type scaling ranged from $1=$ very low to 5 = very high, was used. Examples of items are: I believe that I can wear a mask while working in the barn; I believe that I can wear gloves while working in the barn. The theoretical range for this instrument was 7-35. The higher score showed more self-efficacy toward BPBs (Cronbach $\alpha=0.83$ ).

The General Self-Esteem Scale (GSES) was a nineitem scale developed by the researchers to measure the general self-esteem of brucellosis patients. The response format was based on a two-point scaling (agree $=2$ and disagree $=1$ ). Examples of the items were as follow: I feel that I am a valuable person; I can do my jobs as good as other people. The theoretical range for this scale was 9-18, within which higher scores indicated higher selfesteem among the patients (Cronbach $\alpha=0.81$ ).

The Brucellosis Preventive Behaviours Scale (BPBS) was also a nine-item instrument with a two-point scaling (yes $=2$ and no=1). The items comprised activities that should be conducted to prevent brucellosis. The list of the items is provided in Table 1.

\section{Statistics}

Data were coded numerically and entered into Statistical Package for Social Sciences (SPSS) software, version 20.0 for Windows. The level of significance was considered to be $<0.05$, a priori. Summary statistics and frequency distributions were used to describe and interpret the meaning of data. An additional calculation was performed on the mean score of the variables. The differences between the Empowerment Model constructs by demographic variables were analyzed using one-way ANOVA and t-test or their non-parametric equivalents (Kruskal-Wallis and Man-Whitney U tests). Pearson correlation coefficient was applied to indicate the associations between the Empowerment Model structures and BPBs. Moreover, hierarchical linear regression analysis (HLRA) with enter method was applied to illustrate the variations in BPBs on the basis of the Empowerment Model constructs. HLRA was performed in two blocks to evaluate the efficiency of Empowerment Model constructs over the influence of the other factors. Predictors for the BPBs were classified in two different blocks according to their natures: (Block 1) Demographic characteristics: age, gender, level of education, residency; (Block 2) Empowerment Model constructs: including knowledge, attitude, self-efficacy and self-esteem.

\section{Results}

\section{Demographic characteristics and brucellosis preventive behaviours}

The age of the participants ranged from 17 to 50 years (mean age $=35.13 \pm 9.51) .38 \%$ of the patients were illiterate or with elementary education. 37\% were ranchers and $61 \%$ were rural residents (Table 2 ). Statistically significant differences were found in the BPBs by all the characteristics, except for gender $(P<0.001)$. Applying a series of Kruskal-Wallis and Man-Whitney U tests, the level of performing BPBs was found to be less prevalent among those with lower level of education, ranchers and rural residents.

\section{Brucellosis preventive behaviours among patients}

The most prevalent BPBs among patients were "Fresh cheese usage" (87.3\%)," "time vaccinating of livestock" (51.2\%), "washing hands with soap and water after every contact with cattle secretions" (47.3\%) and "wearing a mask while working in the barn" $(44.9 \%)$, respectively (Table 1).

\begin{tabular}{|c|c|c|c|c|}
\hline \multirow{2}{*}{ Brucellosis preventive behaviors } & \multicolumn{2}{|c|}{ YES } & \multicolumn{2}{|c|}{ NO } \\
\hline & $\mathbf{N}$ & $\%$ & $\mathbf{N}$ & $\%$ \\
\hline Pasteurized milk usage & 16 & $5 \cdot 7$ & 267 & 94.3 \\
\hline Raw milk usage & 85 & 30 & 198 & 70 \\
\hline Fresh cheese usage & 247 & 87.3 & 36 & 12.7 \\
\hline On time vaccinating of the livestock & 145 & 51.2 & 138 & 48.8 \\
\hline Wearing gloves while working in the barn & 84 & 29.7 & 199 & 70.3 \\
\hline Wearing mask while working in the barn & 127 & 44.9 & 156 & 55.2 \\
\hline Disinfecting the obstetric secretions of the livestock in the barn & 12 & 4.2 & 271 & 95.8 \\
\hline Washing the udder of cattle before milking & 4 & 1.4 & 279 & 98.6 \\
\hline Eating raw or partially cooked meat & 103 & 36.4 & 180 & 63.6 \\
\hline Washing hands with soap and water after every contact with the cattle's secretions & 134 & 47.3 & 149 & 52.7 \\
\hline
\end{tabular}




\section{Empowerment Model constructs and brucellosis preventive behaviours}

Pearson's correlation coefficient test revealed statistically significant associations between the BPBs and knowledge $(P<0.01, \mathrm{r}=0.571)$, attitude $(P<0.01, \mathrm{r}=0.172)$ and self-efficacy $(P<0.01, r=0.214)$ (Table 3$)$.

\section{Prediction of brucellosis preventive behaviours by Empowerment Model constructs}

Demographic characteristics of the respondents explained approximately $30 \%$ of the observed variance in BPBs, which was statistically significant $(P<0.001)$ (Table 4). Also, the EM constructs were responsible for, approximately, $51.0 \%$ of change in the observed variance $(P<0.001)$. In the first block, the level of education was the only significant predictor for BPBs $(\Delta \mathrm{R} 2=0.301)$; and, in the second block, knowledge, self-efficacy and the level of education were significant predictors of BPBs $(\Delta \mathrm{R} 2=0.507)$. Patients' knowledge on brucellosis was the strongest predictor for performing BPBs.

\section{Discussion}

The current study investigated the factors associated with BPBs among patients with brucellosis applying the EM. Our findings indicated significant differences in BPBs by the patient's level of education, occupation and residency. The mean score of $\mathrm{BPBs}$ was higher among those with a university education compared to the illiterate and people with low level of education. In the hierarchical regression analysis, the level of education was the only significant predictor of BPBs in the first step of the analysis. In line with these findings, Babaei et al., (11) found significant difference in BPBs by the education level of the ranchers. These findings show that the level of disease prevention literacy among literate people is higher compared to their illiterate counterparts. In addition, Sun et al., (22) reported that education has positive and direct effect on prior knowledge and health literacy. Also, Sohng et al. (23) reported that the mean score of health promoting behaviours was higher among people with a higher level of education. In comparison with the illiterate and those with low level of education in the present study, the patients with the higher levels of education may have had the ability to seek health information from various sources, which, consequently, have led them to a better level of knowledge on the disease and thus perform a higher level of BPBs.

In the present study, when applying Pearson Correlation Coefficient test a significant positive association was found between the knowledge on brucellosis disease and BPBs. Moreover, in the regression analysis, we found that the patients' knowledge on the disease and its prevention was the strongest predictor for BPBs. As Tebug et al. noted, having low knowledge on zoonotic diseases may lead to its prevalence and causes problems in controlling them (24). They also reported that only $15 \%$ of the stockbreeders knew brucellosis as a zoonotic disease (24). Mostafaei et al., (25) reported the students' level of awareness about brucellosis as undesirable. These findings urge the need for designing and implementing educational programmes to raise people's awareness about brucellosis and its prevention.

\begin{tabular}{|c|c|c|c|c|}
\hline Characteristics & $\mathbf{N}(\%)$ & Mean & SD & $\mathbf{P}$ \\
\hline Age (years) & $238(100)$ & 35.1 & 9.5 & \\
\hline \multicolumn{5}{|l|}{ Sex* } \\
\hline Male & $197(69.6 \%)$ & 2.73 & 1.95 & \multirow[t]{2}{*}{$P=0.540$} \\
\hline Female & $86(30.4 \%)$ & 2.51 & 1.29 & \\
\hline \multicolumn{5}{|l|}{ Level of education ** } \\
\hline Illiterate/elementary & $108(38.2 \%)$ & 2.08 & 0.88 & \multirow[t]{3}{*}{$P<0.001$} \\
\hline High school/diploma & $104(37.7 \%)$ & 2.30 & 1.10 & \\
\hline College & $71(25.1 \%)$ & 3.91 & 1.81 & \\
\hline \multicolumn{5}{|l|}{ Employment ${ }^{* *}$} \\
\hline Rancher & $95(33.6 \%)$ & 2.04 & 1.06 & \multirow{5}{*}{$P<0.001$} \\
\hline Farmer & $41(14 \cdot 5 \%)$ & 2.48 & 1.07 & \\
\hline Worker & $26(9.2 \%)$ & 2.65 & 1.67 & \\
\hline Housewife & $62(21.9 \%)$ & 2.40 & 1.05 & \\
\hline Employee & $59(20.8 \%)$ & 3.82 & 1.74 & \\
\hline \multicolumn{5}{|l|}{ Residency ${ }^{*}$} \\
\hline Urban & $110(38.9 \%)$ & 2.94 & 1.72 & \multirow[t]{2}{*}{$P=0.003$} \\
\hline Rural & $173(61.1 \%)$ & 2.42 & 1.21 & \\
\hline
\end{tabular}

*Differences in the means were measured using Man-Whitney U test.

${ }^{* *}$ Differences in the means were measured using Kruskal-Wallis test. 
Table 3 Associations between the Empowerment Model constructs and brucellosis preventive behaviours among patients ( $n=238)$, Chaldoran County, Islamic Republic of Iran, 2013

\begin{tabular}{|c|c|c|c|c|c|c|c|}
\hline & $\mathbf{1}$ & 2 & 3 & 4 & 5 & $\mathrm{M} \pm \mathrm{SD}$ & $\begin{array}{c}\text { Possible } \\
\text { range }\end{array}$ \\
\hline $1=$ Knowledge & 1 & & & & & $5.3 \pm 1.74$ & $0-10$ \\
\hline 2 = Attitude & $0.172^{* *}$ & 1 & & & & $24.17 \pm 2.3$ & $10-50$ \\
\hline $3=$ Self-efficacy & $0.214^{*}$ & $0.296^{* *}$ & 1 & & & $14.85 \pm 3.71$ & $7-35$ \\
\hline 4 = Self-esteem & -0.043 & $0.217^{* *}$ & $0.276^{* *}$ & 1 & & $13.68 \pm 1.97$ & $9-18$ \\
\hline $5=\mathrm{BPBs}^{* * *}$ & $0.571^{* *}$ & $0.131^{* *}$ & $0.261^{* *}$ & -0.018 & 1 & $2.62 \pm 1.45$ & $0-10$ \\
\hline
\end{tabular}

${ }^{*}$ Correlate is significant at the 0.05 level (2-tailed); ${ }^{* *}$ Correlate is significant at the 0.01 level (2-tailed); ${ }^{* * *}$ Brucellosis Preventive Behaviours

Therefore, knowledge on the disease is still a major risk factor for brucellosis morbidity, which should be considered as a core category while designing brucellosis prevention programmes. In the regions with a high prevalence of the disease, a brucellosis prevention campaign may be considered as a strategy in prevention programmes.

Similar with our findings, Tebug et al. in Malawi (24) found that working at a stockyard is a risk factor for brucellosis. However, in the study conducted by Orouji et al., in the rural areas of Khomain County, no significant association was found between occupation and BPBs (10). This difference in the results may be related to the target groups of the studies. In our study, the target group was people with brucellosis with a high risk for not performing the BPBs compared to healthy people in the study of Orouji et al. (10).

The most common high risk behaviours among patients in the present study were consumption of unpasteurized milk and fresh cheese, not wearing a mask while working in the barn, and not washing the cows' udders before milking. Clearly, $69.6 \%$ of the participants reported eating fresh cheese. Similar with this finding, Sufian et al., (9), Earhart et al., (6) and Makita et al., (26) reported the consumption of unpasteurized dairy products as a prevalent risk factor for brucellosis. In the study in Malawi (24), 34\% of the respondents consumed unpasteurized milk. Moreover, Minas et al., (27) in Greece, attributed $8.49 \%$ of the brucellosis infection to dairy products.

In addition, the findings of the present study showed that the majority of the brucellosis patients did not wear gloves and mask while working in the barn, and had direct contact with the obstetric secretions. In fact, in this study $48.8 \%$ of the patients did not use gloves and $70.3 \%$ did not wear a mask while working in the barn. Moreover, $49.9 \%$ reported not disinfecting the obstetrics secretions in the barn and $63.3 \%$ reported not washing their hands after touching faeces and other secretions of livestock. All of these factors may have an important role in brucellosis infection. Earhart et al. (6) reported a significant association between brucellosis infection and having contact with the secretions of aborted animals. The findings of the analysis conducted by Bikas et al. (28) and Cooper et al (29) showed that trauma during animal delivery is an important risk factor for being infected with brucellosis. These findings, again, suggest that patients may not be aware of the ways of brucellosis transmission and they, also, may not consider themselves susceptible to brucellosis.

The mean score for self-efficacy among the brucellosis patients was relatively low, which is similar to those found by Hung et al., on malaria prevention (30). Moreover, a significant association was found between self-efficacy and BPBs in the present study. Further analysis and applying hierarchical regression presented self-efficacy as a significant predictor for BPBs. The association between self-efficacy and high-risk behaviours was confirmed in previous studies (31-33). Self-efficacy is an important precondition for self-management in promoting health behaviours $(34,35)$. These findings suggest that self-efficacy improvement should be a core strategy in planning brucellosis prevention interventions by healthcare providers.

According to the findings of hierarchical regression analysis in the present study, Empowerment Model was able to explain and describe $50.7 \%$ of the behavioural changes in patients afflicted with brucellosis. Moreover,

\begin{tabular}{|c|c|c|}
\hline Step/Variable & B (Step 2) & B (Step 1) \\
\hline \multicolumn{3}{|l|}{ Block 1} \\
\hline Age & -0.029 & -0.047 \\
\hline Level of Education & $0.538^{*}$ & $0.407^{*}$ \\
\hline Gender & 0.048 & 0.057 \\
\hline job & 0.023 & 0.015 \\
\hline Residence & 0.041 & 0.029 \\
\hline \multicolumn{3}{|l|}{ Block 2} \\
\hline Knowledge & & $0.426^{*}$ \\
\hline Attitude & & 0.018 \\
\hline Self-efficacy & & $0.167^{*}$ \\
\hline Self-esteem & & -0.037 \\
\hline$\Delta \mathrm{R}_{2}$ & 0.301 & 0.507 \\
\hline Cumulative $\Delta \mathrm{R}_{2}$ & 0.301 & 0.808 \\
\hline$P$ value & 0.001 & 0.001 \\
\hline
\end{tabular}


among the constructs of the Empowerment Model, knowledge and self-efficacy were the significant predictors of BPBs. In the study conducted by Babaei et al., among the ranchers, self-efficacy was the strongest predictor of BPBs (11). Moreover, several previous studies $(36,37)$ have reported knowledge and self-efficacy as the most powerful predictors of preventive behaviours among different populations. Considering the applicability of Empowerment Model in predicting BPBs in the present study, it can be concluded that Empowerment Model may be considered as an alternate methodological choice while designing educational interventions aiming at $\mathrm{BPBs}$ promotion in the high risk areas.

\section{Limitations}

Considering that the method of data collection in our study was based on self-reporting by patients with brucellosis, there is a possibility for recall bias. Also, as the nature of study was cross-sectional, the generalizability of the findings is warranted. Another limitation may be the lack of information on economic status of patients. Level of income may be a predictor for the level of BPBs among these patients, which could be considered in the present study. Finally, considering the significant asso- ciation between the level of education and BPBs, further research is suggested with more focus on health literacy among patients with brucellosis.

\section{Conclusion}

The results of the present study showed the Empowerment Model as a helpful framework in identifying and predicting the risk factors of BPBs. Promoting knowledge, self-efficacy and disease - specific health literacy may be the core strategies while designing interventional programmes to promote BPBs among the patients in low- and middle-income countries. Moreover, among the constructs of the Empowerment Model, knowledge and self-efficacy were the significant predictors of BPBs. Considering the strength of the Empowerment Model in predicting the cognitive factors associated with BPBs and also the lack of socio-environmental factors in this model, it is suggested to be integrated with other models such as the ecological model or the PRECEDE-PROCEED model, and used as a comprehensive framework while designing health promotion interventions for brucellosis prevention and control.

Funding: None.

Competing interests: None declared.

\section{Facteurs cognitifs associés aux comportements de prévention de la brucellose chez les patients diagnostiqués : application du modèle d'autonomisation \\ Résumé}

Contexte: Dans de nombreux pays, la brucellose est une maladie endémique, en particulier dans la Région de la Méditerranée, ainsi que dans des pays tels que la République islamique d'Iran. En dépit des mesures de prévention de la brucellose adoptées dans différents pays à travers le monde, cette maladie reste un problème de santé publique.

Objectifs: La présente étude avait pour objectif d'examiner les facteurs cognitifs associés aux comportements de prévention de la brucellose chez les patients diagnostiqués à partir du modèle d'autonomisation.

Méthodes : Dans le cadre d'une étude transversale réalisée en 2013, l'ensemble des 238 patients atteints de brucellose dans la circonscription de Chaldoran, en République islamique d'Iran, ont été recrutés. Lors d'un entretien, il a été demandé aux patients de remplir un questionnaire basé sur le modèle d'autonomisation ainsi que sur une échelle des comportements de prévention de la brucellose élaborés par les chercheurs.

Résultats : Des régressions linéaires hiérarchiques multiples ont été réalisées, les comportements de prévention de la brucellose constituant la variable de jugement. En fonction de leur nature, les facteurs prédictifs de cette variable ont été classés en deux groupes distincts. Dans le premier groupe, on a constaté un effet significatif sur les comportements de prévention de la brucellose en fonction des variables démographiques ( $\Delta R 2=0,301)$. Dans le second groupe, les niveaux d'éducation, de connaissances et d'efficacité personnelle constituaient des facteurs prédictifs significatifs $(p<0,001)$ des comportements préventifs de la brucellose $(\Delta \mathrm{R} 2=0,808)$.

Conclusions : Le modèle d'autonomisation a constitué un cadre utile pour prévoir les facteurs de risque associés aux comportements de prévention de la brucellose. Dans les pays à revenu faible et intermédiaire, il est recommandé aux prestataires de soins de santé de prendre en compte les connaissances des patients sur la maladie ainsi que leur niveau d'efficacité personnelle concernant les comportements de prévention de la brucellose comme catégories de base de l'autonomisation dans le processus d'élaboration de programmes de prévention de cette maladie. 


$$
\begin{aligned}
& \text { العوامل الإدراكية المرتبطة بالسلو كيات الوقائية من داء البروسيلات بين المرضى الذين تم تشخيصهم: تطبيق نموذج } \\
& \text { توحيد بابا زادة، حيدر ندريان، سهيلا رنجبران، حامد رضاخاني مقدم، مهر ان أغه ميري }
\end{aligned}
$$

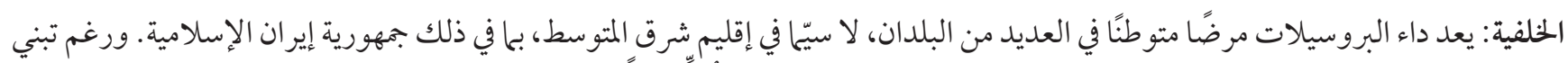

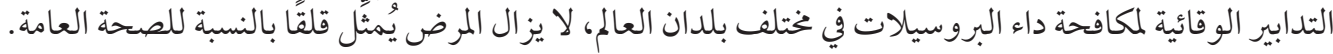

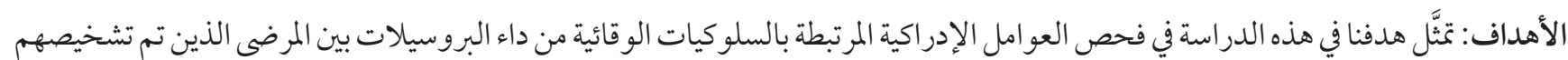
بالمرض باستخدام نموذج التمكين.

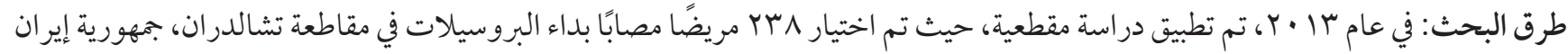

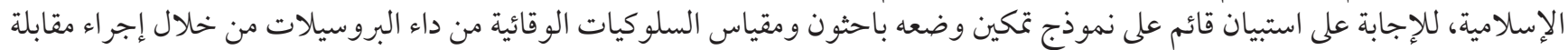

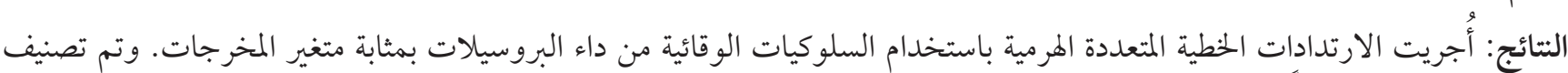

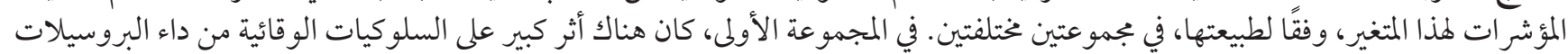

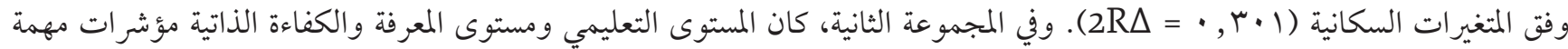

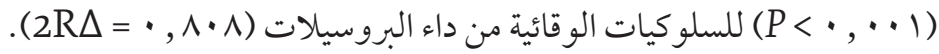

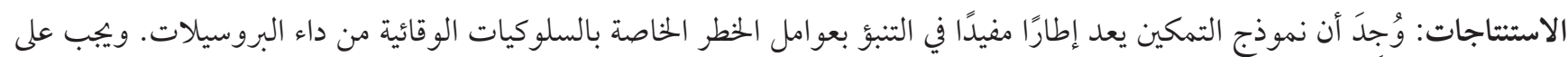

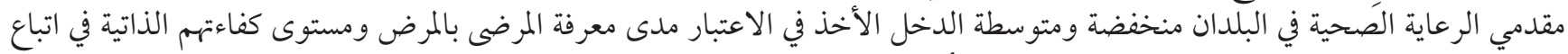

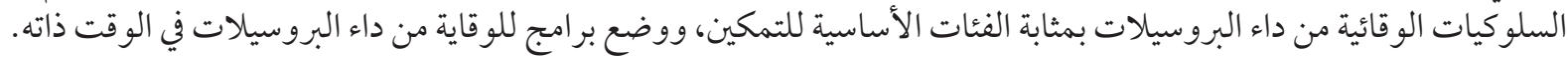

\section{References}

1. Jafari S, Ashrafizadeh SG, Zeinoddini A, Rasoulinejad M, Entezari P, Seddighi S, et al. Celecoxib for the treatment of mild-to-moderate depression due to acute brucellosis: a double-blind, placebo-controlled, randomized trial. J Clin Pharm Ther. 2015;40(4):4416. http://dx.doi.org/10.1111/jcpt.12287

2. de los Ángeles Mantecón M, Gutiérrez MP, del Pilar Zarzosa M, Fernández-Lago L, de Dios Colmenero J, Vizcaíno N, et al. Influence of brucellosis history on serological diagnosis and evolution of patients with acute brucellosis. J Infect. 2008;57(5):397-403. http://dx.doi.org/10.1016/j.jinf.2008.08.005

3. Roushan MRH, Baiani M, Asnafi N, Saedi F. Outcomes of 19 pregnant women with brucellosis in Babol, northern Iran. Trans R Soc Trop Med Hyg. 2011;105(9):540-2. http://dx.doi.org/10.1016/j.trstmh.2011.06.003

4. Olsen S. Brucellosis in the United States: role and significance of wildlife reservoirs. Vaccine. 2010;28:F73-6. http://dx.doi. org/10.1016/j.vaccine.2010.03.059

5. Almasi-Hashiani A, Khodayari M, Eshrati B, Shamsi M. Factors affecting the interval between the onset and diagnosis of brucellosis in Markazi Province, Iran (2010-11). Arak Medical University Journal. 2012;14(7):21-30.

6. Earhart K, Vafakolov S, Yarmohamedova N, Michael A, Tjaden J, Soliman A. Risk factors for brucellosis in Samarqand Oblast, Uzbekistan. Int J Infect Dis. 2009;13(6):749-53. http://dx.doi.org/10.1016/j.ijid.2009.02.014

7. World Health Organization Regional Office for South-East Asia (WHO/SEARO). A brief guide to emerging infectious diseases and zoonoses. New Delhi: WHO/SEARO; 2014 (http://apps.who.int/iris/bitstream/10665/204722/1/B5123.pdf?ua=1)

8. Farahani S, Shah Mohamadi S, Navidi I, Sofian M. An investigation of the epidemiology of brucellosis in Arak City, Iran,(20012010). Arak Medical University Journal. 2012;14(7):49-54.

9. Sofian M, Aghakhani A, Velayati AA, Banifazl M, Eslamifar A, Ramezani A. Risk factors for human brucellosis in Iran: a case-control study. Int J Infect Dis. 2008;12(2):157-61. http://dx.doi.org/10.1016/j.ijid.2007.04.019

10. Orouji M, Hashemi S, Hazavehei S, Charkazi A, Jvaheri J, Moazeni M. The positive impact of educational intervention program based on precede model on preventive behaviors to reduce Brucellosis in the rural people of Khomein. Research Development in Nursing and Midwifery. 2012;1:51-60.

11. Babaei V, Babazadeh T, Kiani A, Garmaroodi G, Batebi A. Investigating the Effective Factors in Preventive Behaviors of Brucellosis in Stockbreeder of Charaoymaq County: A Health Belief Model. Journal of Fasa University of Medical Sciences 2015;5(4):4-9.

12. Plotnikoff RC, Trinh L, Courneya KS, Karunamuni N, Sigal RJ. Predictors of aerobic physical activity and resistance training among Canadian adults with type 2 diabetes: An application of the Protection Motivation Theory. Psychol Sport Exerc. 2009;10(3):320-8. http://dx.doi.org/10.1016/j.psychsport.2008.10.002 
13. Jahangiry L, Nadrian H, Mahdavi B, Allahvrdipour H, Kousha A. Primary development and psychometric properties of PRECEDE Model based scales for Brucellosis prevention among an Iranian Rural Population. Arch Clin Infect Dis. In Press(In Press):e62957. http://dx.doi.org/10.5812/archcid.62957.

14. Kickbusch I, Nutbeam D. Health promotion glossary. Geneva: World Health Organization; 1998.

15. Sousa P, Antunes A, Carvalho J, Casey A. Parental perspectives on negotiation of their child's care in hospital. Nurs Child Young People. 2013;25(2):24-8. http://dx.doi.org/10.7748/ncyp2013.03.25.2.24.e142

16. Mehri A, Solhi M, Garmaroudi G, Nadrian H, Sighaldeh SS. Health promoting lifestyle and its determinants among university students in Sabzevar, Iran. Int J Pre Med. 2016; 7: 65. http://dx.doi.org/10.4103/2008-7802.180411

17. Heidari M, Alhani F, Kazemnejad A, Moezzi F. The effect of empowerment model on quality of life of Diabetic adolescents. Iran J Pediatr. 2007;17 Suppl 1:87-94.

18. Masoodi R, Allhani F, Moghadassi J, Ghorbani M. The effect of family-centered empowerment model on skiii, atittude, and knowledge of mutiple sclerosis caregivers. Journal of Birjand University of Medical Sciences. 2010;17(2):87-97.

19. Kargar Najafi M, Borhani F, Dortaj R, Sabzevari S. The Effect of Family-Centered Empowerment Model on the Mothers' Knowledge and Attitudes about Thalassemia Disorder. Iran J Ped Hematol Oncol. 2011;1(3):98-103.

20. Rajabi R, Sabzevari S, Borhani F, Haghdoost A, Bazargan N. The effect of family-centered Empowerment Model on quality of life school age children with asthma. J Health Prot Manage. 2013;2(4):7-15.

21. Teymouri F, Alhani F, Kazemnejad A. The effect of family-centered empowerment model on the Quality of life of school-age asthma children. 2011.

22. Sun X, Shi Y, Zeng Q, Wang Y, Du W, Wei N, et al. Determinants of health literacy and health behavior regarding infectious respiratory diseases: a pathway model. BMC Public Health. 2013;13(1):1.

23. Sohng KY, Sohng S, Yeom HA. Health-Promoting Behaviors of Elderly Korean Immigrants in the United States. Public Health Nurs. 2002;19(4):294-300. http://dx.doi.org/10.1046/j.1525-1446.2002.19409.x

24. Tebug S, Njunga GR, Chagunda MG, Mapemba JP, Awah-Ndukum J, Wiedemann S. Risk, knowledge and preventive measures of smallholder dairy farmers in northern Malawi with regard to zoonotic brucellosis and bovine tuberculosis. Onderstepoort Journal of Veterinary Research. 2014;81(1):01-6.

25. Mostafei G, Eskandari E, Ghazizadeh S, Nasrollahzadeh Z, Hosseindoost GR, Gilasi HR, et al. Determining the Students' Knowledge of Kashan University of Medical Sciences about Brucellosis. Scientific Journal of Ilam University of Medical Sciences. 2013;21(4):30-6.

26. Makita K, Desissa F, Teklu A, Zewde G, Grace D. Risk assessment of staphylococcal poisoning due to consumption of informally-marketed milk and home-made yoghurt in Debre Zeit, Ethiopia. Int J Food Microbiol. 2012;153(1):135-41. http://dx.doi. org/10.1016/j.ijfoodmicro.2011.10.028

27. Minas M, Minas A, Gourgulianis K, Stournara A. Epidemiological and clinical aspects of human brucellosis in Central Greece. Jpn J Infect Dis. 2007;60(6):362.

28. Bikas C, Jelastopulu E, Leotsinidis M, Kondakis X. Epidemiology of human brucellosis in a rural area of north-western Peloponnese in Greece. Eur J Epidemiol. 2002;18(3):267-74. http://dx.doi.org/10.1023/A:1023368420840

29. Cooper CW. Risk factors in transmission of brucellosis from animals to humans in Saudi Arabia. Trans R Soc Trop Med Hyg. 1992;86(2):206-9. http://dx.doi.org/10.1016/0035-9203(92)90575-W

30. Hung W-S, Hu SC, Hsu Y-C, Chen K-L, Chen K-H, Yu M-C, et al. Factors affecting the use of anti-malaria preventive measures among Taiwan immigrants returning to malaria-endemic regions. Travel Med Infect Dis. 2014;12(4):370-7. http://dx.doi. org/10.1016/j.tmaid.2013.07.001

31. Kanera IM, Bolman CA, Mesters I, Willems RA, Beaulen AA, Lechner L. Prevalence and correlates of healthy lifestyle behaviors among early cancer survivors. BMC Cancer. 2016;16(1):4. http://dx.doi.org/10.1186/s12885-015-2019-x

32. Vakili M, Rahaei Z, Nadrian H, YarMohammadi P. Determinants of oral health behaviors among high school students in Shahrekord, Iran based on Health Promotion Model. . American Dental Hygienists Association. 2011 85(1):39-48.

33. Morowatisharifabad MA, Fallahi A, Nadrian H, Haerian A, Babaki BN. Interdental Cleaning Behaviour and Its Relationship with Psychological Constructs Based on the Transtheoretical Model. Oral Health Prev Dent. 2011;9(3):211-20.

34. Sarkar U, Fisher L, Schillinger D. Is self-efficacy associated with diabetes self-management across race/ethnicity and health literacy? Diabetes Care. 2006;29(4):823-9. http://dx.doi.org/10.2337/diacare.29.04.06.dc05-1615

35. Ali M, Haidar N, Ali MM, Maryam A. Determinants of seat belt use among drivers in Sabzevar, Iran: a comparison of theory of planned behavior and health belief model. Traffic Inj Prev. 2011;12(1):104-9. http://dx.doi.org/10.1080/15389588.2010.535227

36. Shirzadi S, Nadrian H, Asghari Jafarabadi M, Allahverdipour H, Hassankhani H. Determinants of mammography adoption among Iranian women: What are the differences in the cognitive factors by the stages of test adoption?. Health care women int. 2017;38(9):956-70. http://dx.doi.org/10.1080/07399332.2017.1338705

37. Taymoori P, Lubans D, Berry TR. Evaluation of the health promotion model to predict physical activity in Iranian adolescent boys. Health Educat Behav. 2010;37(1):84-96. 